\title{
The role of intracranial pressure in glaucoma and therapeutic implications
}

\author{
Alex J. Baneke ${ }^{1} \cdot$ James Aubry ${ }^{2} \cdot$ Ananth C. Viswanathan $^{3} \cdot$ Gordon T. Plant $^{4}$ \\ Received: 11 October 2019 / Accepted: 21 October 2019 / Published online: 27 November 2019 \\ (c) The Author(s), under exclusive licence to The Royal College of Ophthalmologists 2019
}

\begin{abstract}
Despite glaucoma being the second leading cause of blindness globally, its pathogenesis remains incompletely understood. Although intraocular pressure (IOP) contributes to glaucoma, and reducing IOP slows progress of the disease, some patients progress despite normal IOP (NTG). Glaucomatous damage causes characteristic cupping of the optic nerve where it passes through the lamina cribrosa. There is evidence that cerebrospinal fluid (CSF) within the optic nerve sheath has a different composition from CSF surrounding the brain. Furthermore, fluctuations in CSF flow into the optic nerve sheath may be reduced by trabeculae within the sheath, and on standing intracranial pressure (ICP) within the sheath is stabilised at around $3 \mathrm{mmHg}$ due to orbital pressure. Blood pressure has been linked both to glaucoma and ICP. These facts have led some to conclude that ICP does not play a role in glaucoma. However, according to stress formulae and Laplace's Law, stress within the lamina cribrosa is dependent on the forces on either side of it, (IOP and ICP), and its thickness. On lying flat at night, ICP between the brain and optic nerve sheath should equalise. Most evidence suggests ICP is lower in glaucoma than in control groups, and that the lamina cribrosa is thinner and more posteriorly displaced in glaucoma. Subjects who have had ICP reduced have developed signs of glaucoma. This review finds most evidence supports a role for low ICP in the pathogenesis of glaucoma. Caffeine, theophylline and vitamin A may increase ICP, and could be new candidates for an oral treatment.
\end{abstract}

\section{Methodology}

PubMed was searched online using the combinations of terms: glaucoma, intracranial pressure, cerebrospinal fluid pressure, translaminar pressure gradient, lamina cribrosa, and blood pressure. Abstracts were screened and articles read if considered relevant.

Alex J. Baneke

alexbaneke@yahoo.co.uk

1 Moorfields Eye Hospital NHS Foundation Trust, London, UK

2 General Electric Oil and Gas, Florence, Italy

3 NIHR Biomedical Research Centre for Ophthalmology at Moorfields Eye Hospital NHS Foundation Trust and UCL Institute of Ophthalmology, London, UK

4 Institute of Neurology, University College London, London, UK

\section{Background}

Glaucoma is the second leading cause of blindness globally, but its pathogenesis remains incompletely understood [1]. The disorder is characterised by optic nerve damage with corresponding visual field loss. Lowering intraocular pressure (IOP) can slow the course of disease but patients can progress despite apparently well controlled IOP [2,3]. Patients with glaucoma but without raised IOP are said to have normal tension glaucoma (NTG), and these comprise up to half of cases in the United States of America, and up to $90 \%$ of cases in Japan $[4,5]$. Conversely, some patients with high IOP do not develop glaucoma, a condition which is referred to as ocular hypertension (OHT) [6]. Other factors, therefore, must play a role in the development of glaucoma. These may include blood flow at the optic nerve head, vasospasm, autoimmune factors, and genetic predisposition [7-10].

Glaucomatous optic neuropathy has traditionally been thought to occur due to pressure effects on the optic nerve affecting axonal flow, resulting in retrograde retinal ganglion cell (RGC) damage. Pressure effects are assumed to occur predominantly at the optic nerve head, where 
neurones turn to pass through the lamina cribrosa (LC), a collagenous membrane with elastic properties, anchored to the more rigid scleral wall of the eye [11]. The pressures on each side of the LC-IOP and optic nerve sheath subarachnoid space pressure (ONSP) - differ in most situations. If we assume ONSP is similar to intracranial cerebrospinal fluid pressure (ICP), IOP tends to be higher than ICP $(14.7 \pm 2.8 \mathrm{mmHg}$ vs $12.9 \pm 1.9 \mathrm{mmHg}$ in a supine position) $[12,13]$. This difference is further pronounced when standing, when ICP drops to -10 to $0 \mathrm{mmHg}$ at eye level because it is within a vertically oriented hydrostatic system, whereas IOP drops by only $2-4 \mathrm{mmHg}[14,15]$. The translaminar pressure gradient (TLPG) is calculated as the difference in pressure across the LC over its thickness [16]. The LC is impermeable to vitreous and CSF, otherwise there would be no pressure gradient across it. The TLPG will affect the distortion of the LC and the stresses within it. It is tempting to believe that when the TLPG is high the LC visibly bows away from the observer (glaucomatous cupping) whereas if the TLPG is negative, such as in raised ICP situations, the nerve appears to bow towards the centre of the globe (papilloedema). In reality papilloedema is due to impaired axonal transport leading to axonal swelling in raised ICP, and glaucomatous cupping due to loss of the glial prelaminar portion of the optic nerve head [17]. However, there is evidence that suggests the LC does move marginally away from the globe in glaucoma [18-20]. The force exerted on the optic nerve as it passes through the LC will be dependent on the gradient of the forces across it, which may explain why nerve damage occurs both in glaucoma and in conditions such as idiopathic intracranial hypertension (IIH). It should be noted, however, that although raised ICP can occur without the development of papilloedema, whether visual loss can occur in that situation is not certain [21].

The pressure on the cerebral side of the LC in the optic nerve subarachnoid space (ONS) may not be identical to ICP. The ONS contains septa which may alter fluid flow, and the orbital tissue pressure around the ONS may collapse the ONS when ICP drops on standing [22]. For a mechanical theory implicating low ICP in glaucoma to be valid, ICP needs to be transmitted to the LC via the ONS. A further factor addressed in this article is whether ICP is confounded by being related to blood pressure (BP). Studies have linked NTG to systemic hypotension, and hypotension may lower ICP [23, 24]. If ICP is lower in glaucoma, is this causation or simply because both are influenced by systemic hypotension?

Multiple studies have found ICP to be lower in patients with glaucoma or NTG than in control groups, which supports a role for low ICP in the pathogenesis of glaucoma [13, 25-27]. This review examines the role of ICP in glaucoma, and considers implications for disease management.

\section{Stress forces at the lamina cribrosa}

Stress is calculated as force over area applied to or within a material. Stress causes strain, which is calculated as the extension of the material over its length. In the LC, stress may damage nerve fibres and blood vessels, and the resultant strain is seen as deformation.

There are two main calculations required to ascertain stress in the LC. One calculates the forces acting directly at the LC from forces or pressures acting on either side of the membrane (IOP and ICP). The second calculates the hoop stress within the sclera (according to Laplace's Law) [28]. Depending on the rigidity of the sclera, a proportion of the hoop stress will be transferred to the LC and the structures running through it.

The forces acting on either side of the LC can be seen in Fig. 1. If we assume the sclera is entirely rigid, then these are the only forces that apply.

Referencing Roark and Young, Formulas for Stress and Strain [29], stress in the LC is proportional to the pressure difference across the LC, times the radius squared over the thickness squared.

$$
\sigma \propto \frac{p r_{m}^{2}}{t^{2}}
$$

In other words,

$$
\mathrm{LC} \text { stress }=(\mathrm{IOP}-\mathrm{ICP}) \mathrm{LC} \operatorname{radius}^{2} / \mathrm{LC} \text { thickness }{ }^{2}
$$

However, the sclera is not entirely rigid, and therefore a degree of hoop stress within the sclera is transmitted to the LC. Hoop stress is calculated according to Laplace's Law for forces within a sphere:

Wall (hoop) stress $=($ internal pressure $\times$ sphere radius $)$ $/(2 \times$ wall thickness $)$

In the case of the eye,

Scleral hoop stress $=($ IOP $\times$ globe radius $)$

$$
/(2 \times \text { scleral thickness })
$$

Downs et al. believe hoop stress (largely determined by IOP), may have a larger impact on LC stress than ICP [28]. However, though the effect of IOP is likely more significant than ICP, multiple models of optic nerve head biomechanics have listed ICP as an important factor contributing to stress and biomechanics at the optic nerve head [30-32]. Tong et al. modelled the effect of IOP and ICP on LC depth and peak strain [32]. They found that as IOP increases, LC depth and peak strain rise, whereas as ICP increases, LC depth and peak strain fall. The size of the effects of IOP and ICP on LC depth were equivalent, whereas the effect of IOP 

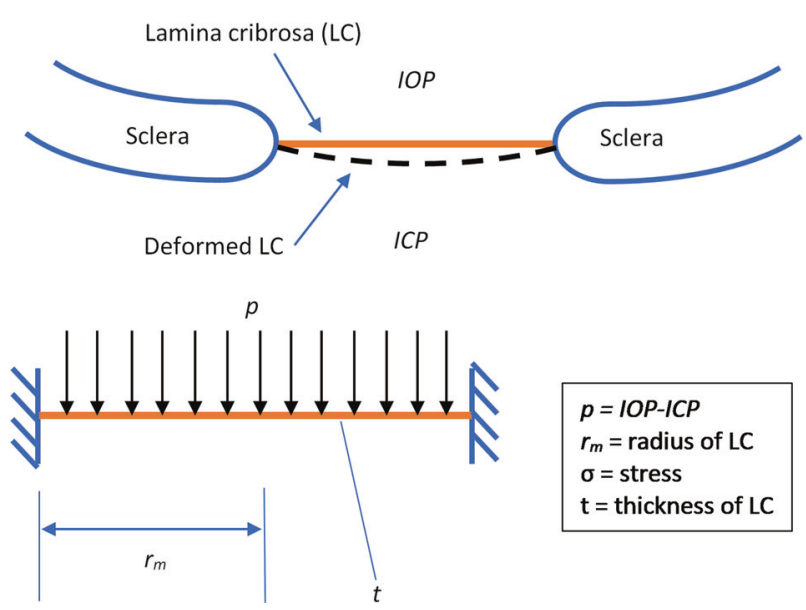

Fig. 1 Forces acting on the lamina cribrosa

on LC peak strain was three times larger than that of ICP. A stiffer sclera increased LC depth but decreased LC peak strain, while it increased the contribution of ICP to peak strain. Sclera stiffens with age, so ICP may play a more important role in glaucoma in older patients.

If IOP contributes to glaucoma via a direct mechanical effect on the optic nerve at the LC, it seems likely that ICP also plays a role.

\section{The optic nerve sheath subarachnoid space and changes in CSF circulation}

RGC axons of the optic nerve pass through pores in the LC to the optic nerve subarachnoid space (ONS). The LC is a collagenous membrane attached to the more rigid surrounding sclera. On one side the LC is exposed to IOP from the vitreous, and on the other to the pressure in the ONS, which likely bears a close relationship to ICP.

Due to difficulties measuring the LC and ONS pressure in humans, much evidence regarding pressure effects comes from animal models. Hou et al. inserted pressure-sensitive probes into the ONS of eight dogs, and shunted CSF to see how ONS pressure varied with ICP [33]. They revealed that ICP and ONS pressure were correlated within a certain pressure range. Retrolaminar pressure stabilised below 3 $\mathrm{mmHg}$, suggesting a mechanism by which ONS pressure is maintained when ICP drops. This may occur due to collapse of the ONS from surrounding orbital tissue pressure when ICP drops on standing [16, 22]. Morgan et al. carried out a similar experiment on anaesthetised dogs, using pressuresensitive micropipettes to measure IOP, retrolaminar pressure, ICP and ONS pressure [34]. BP was kept stable while IOP and ICP were varied using infusions of Krebs solution into the anterior chamber and lateral ventricle. The TLPG was measured directly by advancing a pipette from the vitreous through the LC into the optic nerve. Above ICP of
$1.3 \pm 0.6 \mathrm{mmHg}$, retrolaminar pressure moved in line with ICP. However, when ICP fell below $1.3 \mathrm{mmHg}$, retrolaminar pressure remained stable. Above ICP of $-0.5 \pm$ $0.3 \mathrm{mmHg}$, ONS pressure was equivalent to ICP. The TLPG was measured for 17 animals with varying IOP and ICP. TLPG was then plotted against IOP - ICP. This showed a strong correlation $(r=0.93, p<0.01)$. This not only backs up the findings of the previous study by Hou et al. that ONS pressure is equivalent to ICP above somewhere between -0.5 and $5 \mathrm{mmHg}$, but it also shows that the TLPG in anaesthetised dogs is directly dependent on IOP and ICP. Orbital tissue pressure $(3 \mathrm{mmHg})$ in humans may prevent ONS pressure falling below this level when standing.

The structure of the ONS may affect the transfer of ICP to the LC. Killer et al. performed a histological analysis of 12 human optic nerves using electron microscopy [22]. They found a series of collagenous trabeculae and septa within the ONS, connected by perforations. This structure may reduce the speed of CSF flow and contribute to homeostasis of ICP at the LC in order to stabilise the TLPG. The observation that nerves can be affected to differing degrees by raised ICP further supports the idea that ICP may not be continuous across the entire subarachnoid space [35]. Equally, optic canal size has been correlated with nerve damage and more severe papilloedema in IIH independently of ICP [36].

Other studies have looked at CSF inflow to the ONS. Mathieu et al. injected a fluorescent tracer into the CSF of 2month old $(n=9)$ and 10-month old $(n=8)$ DBA/2J glaucoma mice and age-matched controls $(n=16)$ [37]. Tracer distribution was assessed using confocal microscopy of optic nerve cross sections. In the 10-month-old group, CSF tracer intensity and signal distribution were significantly decreased $(p<0.005)$, suggesting that glaucomatous mice have reduced inflow of CSF to the ONS. Killer et al. examined CSF exchange between the ONS and intracranial space in 18 NTG patients and four controls using CT cisternography [38]. Subjects underwent LP to remove $10 \mathrm{ml}$ of CSF and inject $10 \mathrm{ml}$ of contrast agent (iopamidol) before undergoing $\mathrm{CT}$ and measurement of contrast levels in the ONS and basal cisterns (in Hounsfield Units). Mean density of contrast agent in the ONS, (but not in the basal cisterns) was significantly less in the NTG group than the control group $(p<0.006)$. This study again suggests impaired inflow of CSF to the subarachnoid space in NTG patients. These papers assume concentration of a contrast agent within the CSF can be used to demonstrate distribution of CSF. It is possible that the structure of the ONS prevents influx of contrast more significantly than it prevents influx of CSF.

CSF entry to the ONS may be impaired both in glaucoma and in papilloedema. Inflow of CSF to the optic nerve may also be important for nutrient delivery and toxic metabolite 
clearance. Killer et al. have described an "optic nerve sheath compartment syndrome" in one patient with optic nerve sheath meningioma [39]. CSF samples from the patient's ONS showed elevated levels of albumin, IgG, and betatrace protein compared with lumbar CSF, supporting the theory that the composition of CSF in the ONS in pathological states may differ to that of CSF elsewhere. However, in this patient the sample of "CSF" may have been composed of interstitial fluid originating in the optic nerve itself. A proportion of CSF is not produced in the choroid plexus but originates as interstitial fluid from perivascular spaces [40]. The ONS likely has a higher proportion of this fluid than CSF elsewhere.

On the other hand, studies have shown optic nerve sheath diameter (ONSD) is correlated with ICP and can be used to non-invasively detect changes in ICP with MRI or ultrasound [41-43]. This suggests ICP is transmitted to the ONS. Cennamo et al. compared ONS diameter at 2-5 mm behind the globe in 53 eyes of 27 patients with glaucoma and compared them with 64 normal eyes of 32 controls. ONS was measured with A-scan ultrasound. They showed ONS was significantly smaller in glaucomatous eyes compared with normal eyes $(p=0.001)$ [44]. Conversely, Killer et al. found enlarged ONSD measured by CT in 38 NTG patients undergoing CT cisternography and normal ICP measured by LP [45]. ONSD was compared with 38 eyes of 38 controls who had had standard cranial CT performed previously as part of a work-up for suspected stroke. However, the control group was not a representative sample (they were undergoing CT for suspected stroke), and they did not undergo CT cisternography or LP. The authors comment on the ICP in the NTG group without comparing with their control group. This study may simply show that CT cisternography increases ONSD.

CSF turnover approximately halves from birth to old age, and is significantly reduced in Alzheimer's and normal pressure hydrocephalus (NPH) [46, 47]. This may cause a build-up of neurotoxins. Some studies suggest patients with these two diseases have a higher prevalence of glaucoma, and glaucoma prevalence increases with age [48, 49]. Conversely a large longitudinal study found no increased risk of Alzheimer's in patients with glaucoma [50]. As in the CSF of Alzheimer's and NPH patients, the vitreous fluid of patients with glaucoma contains low levels of $\beta$-amyloid and high levels of tau [51]. While reduced CSF turnover and build-up of neurotoxins may play a role in these three diseases, this does not rule out the role of low ICP in the pathogenesis of glaucoma.

The fact that the ONS is a blind-ended sheath, is lined with perforated septa and trabeculae, and is affected by orbital tissue pressure, likely prevents acute fluctuations in ONS pressure. These factors may also prevent ONS pressure falling below a certain level when standing. This may have protective significance. However, ICP will be transmitted to the LC, as the subarachnoid space is continuous with the ONS. When lying flat at night, ICP in the brain rises. Therefore, these structural factors will have less influence on ONS pressure, and ICP measured in the lateral decubitus position (as in the case of studies relating to ICP measured by lumbar puncture), can be considered as similar to ONS pressure when lying flat. There is likely, however, to be a reduced turnover of CSF within the ONS, and this may cause a reduction in clearance of neurotoxins, which may contribute to the pathogenesis of glaucoma via an entirely different mechanism than an increase in the TLPG.

\section{The lamina cribrosa}

If the TLPG contributes to glaucomatous optic neuropathy, a thinner LC should also contribute, as it would lead to a higher TLPG. Park et al. measured LC thickness using enhanced depth imaging optical coherence tomography (EDI OCT) in 137 glaucoma patients (NTG and POAG) and 49 controls [52]. They found the LC was significantly thinner in POAG patients than controls $(237.82 \pm 40.23 \mu \mathrm{m}$ vs $348.14 \pm 23.41 \mu \mathrm{m})$, and was significantly thinner in NTG patients than POAG $(175.11 \pm 22.60 \mu \mathrm{m}$ vs $237.82 \pm$ $40.23 \mu \mathrm{m}$, all $p<0.001)$.

Kwun et al. compared 102 eyes of 51 NTG patients with unilateral visual field (VF) defect and 47 eyes of 47 normal controls [53]. Optic nerves were scanned using swept source (SS) OCT. LC thickness was measured and correlated with VF mean deviation (MD). They found mean LC thickness of normal fellow eyes was thicker than VFaffected eyes in NTG patients $(p<0.001)$, but thinner than normal eyes $(p<0.001)$. In VF-affected eyes, areas of the LC correlated with a VF defect were significantly thinner than horizontally contralateral locations $(p<0.001)$.

Jonas et al. performed a histological analysis of the LC in 29 highly myopic glaucomatous eyes and 7 highly myopic normal eyes, and compared them with a control group composed of 42 eyes enucleated due to malignant choroidal melanoma (non-highly myopic normal group) and 11 eyes affected by angle-closure glaucoma (non-highly myopic glaucomatous group) [54]. They found open angle glaucoma, angle-closure glaucoma and myopia were significantly associated with a thinner LC $(p<0.001)$. Bae et al. found that optic nerve head radius on OCT was significantly correlated with myopia [55]. Girkin et al. compared the structure of the LC in 19 cadaveric eyes of African descent with 45 cadaveric eyes of European descent [56]. They found the LC in African eyes was significantly thinner with a significantly higher radius. These studies may explain why glaucoma is more prevalent in AfricanCaribbeans and high myopes, (a thinner LC leading to 
increased TLPG, and a greater LC radius leading to increased stress), and why in some patients parts of the optic disc rim are more vulnerable to damage than others (corresponding with thinner parts of the LC) [57, 58]. A thinner LC could also cause nerve damage via greater distortion.

The TLPG should push the LC towards the brain (IOP is higher than ICP), so if there is some deformability in the LC it should be more posteriorly displaced in glaucoma than in normal subjects. Li et al. used EDI OCT to measure LC depth in 26 high tension glaucoma (HTG), 26 NTG, and 25 normal patients [18]. LC depths were significantly greater in HTG than in NTG eyes and in NTG than normal eyes $(p<$ 0.05 ). The difference between HTG and NTG eyes suggests non-mechanical factors may also contribute to NTG. Kim et al. used SS OCT to compare peripheral LC depth in 90 patients with POAG to 90 age-matched controls [19]. LC depth was significantly higher in POAG patients than in controls $(p<0.05)$. Multivariate regression showed increased LC depth was significantly associated with increased baseline IOP and decreased VF MD (all $p<0.05$ ).

Lee et al. performed EDI spectral domain (SD)-OCT pre and post treatment on 100 eyes of 100 patients either newly diagnosed with glaucoma or who had undergone trabeculectomy surgery [59]. Mean IOP was reduced from 21.2 to $10.5 \mathrm{mmHG}(p<0.001)$ and mean LC depth reduced from $585 \pm 161 \mu \mathrm{m}$ to $529 \pm 127 \mu \mathrm{m}(p<0.001)$. This fits with a reduction in IOP causing a reduction in the TLPG and therefore a reduction in the posterior displacement of the LC. However, in $41 \%$ of eyes (primarily in older patients) LC position did not reverse, suggesting structural factors play a role in LC deformation.

Yan et al. carried out an experimental study on ten pairs of cadaveric human eyes [60]. Ten eyes were exposed to 50 $\mathrm{mmHg}$ of pressure for $24 \mathrm{~h}$ and ten control eyes to $5 \mathrm{mmHg}$ for $24 \mathrm{~h}$ before being fixed. Photomicrographs were used to analyse the shape change, and demonstrated elevated IOP caused the LC to deflect posteriorly without changing its thickness, suggesting dominant shear forces at the periphery of the LC, which is in keeping with the observation of focal rim damage in glaucoma.

Perez-Lopez et al. report a case of a 28-year-old patient who underwent optic nerve sheath fenestration for IIH that suggests alterations in ONS pressure can also cause displacement of the LC [61]. The patient underwent EDI SDOCT pre op and on day 1 post op. The anterior surface of the patient's LC reversed its preoperative position by an average of $137 \mu \mathrm{m}$ post op. Morgan et al. experimentally adjusted IOP and ICP in eight dogs, and found that increasing IOP caused posterior LC displacement, whereas increasing ICP caused anterior LC displacement [62].

Conversely, Hayreh argues that the LC is a firm band of connective tissue that does not distort significantly, and that therefore ICP does not play a significant role in glaucoma
[17]. They report that studies on enucleated human and primate eyes demonstrated bowing back of the LC by only $15-86 \mu \mathrm{m}$ when IOP was increased acutely to $30-60 \mathrm{mmHg}$ [60]. However, the acute situation in cadaveric human eyes or primate eyes may not mirror reality, $86 \mu \mathrm{m}$ may be significant when LC thickness is $378.1 \mu \mathrm{m}$, and further deformation may occur over time [63]. Regardless, referencing the formula outlined earlier in this article, although LC deformation will vary depending on its stiffness, the stress in the LC and structures running through it will not.

According to the formula in Fig. 1, increasing LC radius should increase stress on the LC. Equally, Sigal developed a computational model of the eye that suggests peak tensile strain within the LC will increase as LC radius increases, though strain within the prelamina neural tissue may reduce in the presence of stiff postlaminar neural tissue or compliant sclera [64]. While Afro-Caribbean and myopic subjects tend to have a larger LC radius and a higher risk of glaucoma, this literature review revealed no papers that have examined a direct correlation between LC radius and glaucoma; this requires further investigation [55-58].

\section{Is ICP lower in patients with glaucoma?}

The most convincing studies linking low ICP with glaucoma are two large retrospective reviews and two prospective studies by two groups where LP was used to measure ICP (Table 1) [13, 26, 27, 65]. Ren et al. prospectively compared ICP in 14 NTG patients, 29 POAG patients and 71 age-matched controls [13]. The controls underwent LP (in the lateral decubitus position) for neurological investigation. Exclusion criteria were any factors or disorders that could influence ICP. NTG patients had not used glaucoma medication for at least 1 month, while the POAG group continued on medication. TLPG was calculated as IOP - ICP. ICP was significantly lower in the NTG group than the POAG group $(9.5 \pm 2.2 \mathrm{vs} 11.7 \pm 2.7 \mathrm{mmHg}$, $p=0.01$ ), in whom it was significantly lower than the control group (11.7 vs $12.9 \pm 1.9 \mathrm{mmHg}, p<0.001)$. In a multivariate analysis, VF loss was significantly $(p=0.005)$ associated with the TLPG, whereas the IOP and ICP alone were not significantly associated. This suggests a correlation between the TLPG and glaucoma is not due simply to the inclusion of IOP in the formula. In the control group, ICP was significantly correlated with systolic and mean BPs $(r=0.24, p=0.04)$ and IOP $(r=0.76, p<0.05)$. The TLPG was not significantly associated with BP $(p=0.97)$. In glaucoma groups, there was no significant relationship between IOP, ICP, and BP, or between TLPG and BP. All groups had similar BPs. In this group there was no evidence for the role of $\mathrm{BP}$ as a confounder when analysing the relationship between glaucoma and ICP. 


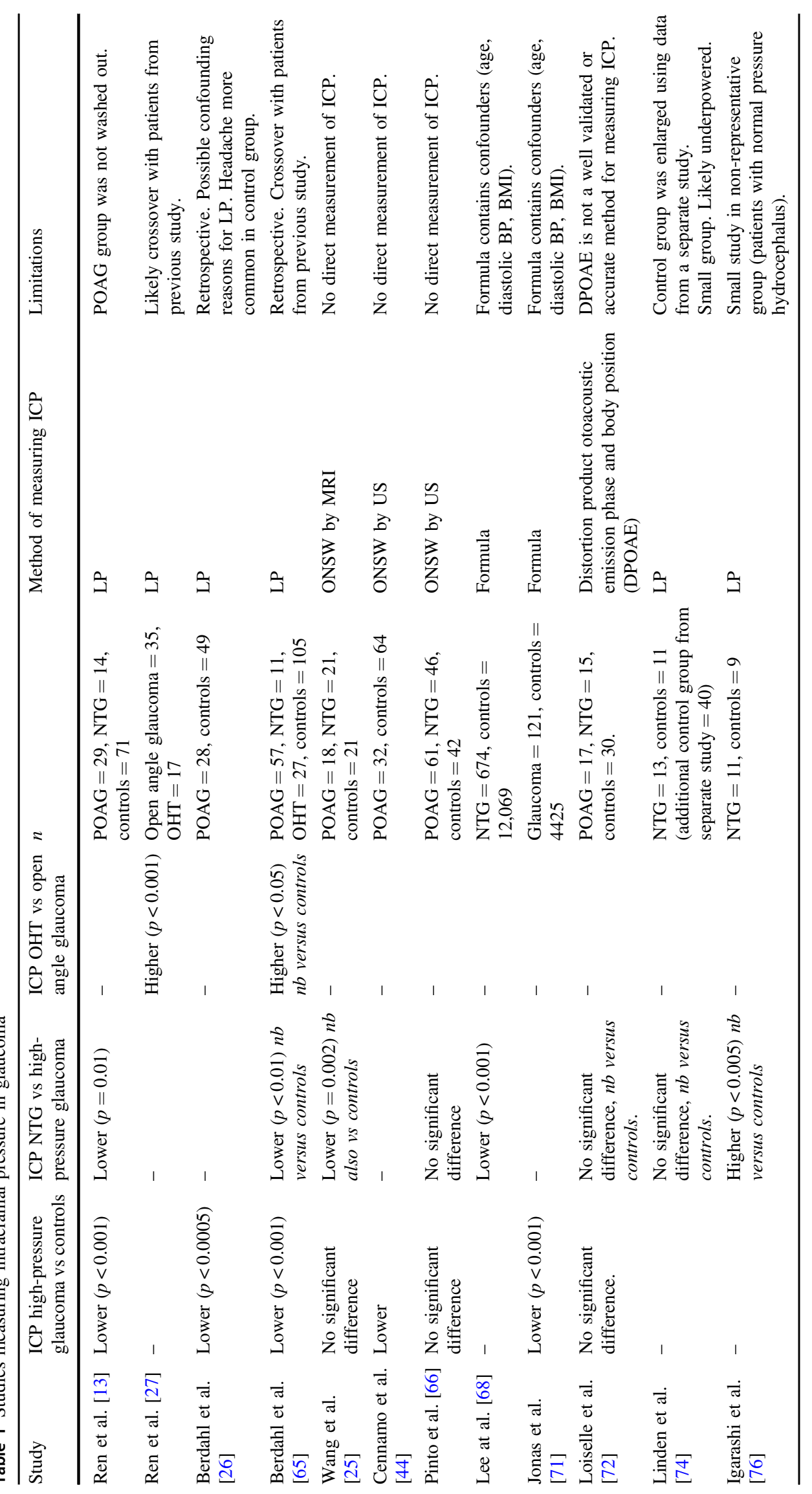


Ren et al. published another prospective study correlating neuroretinal rim area measured by confocal scanning laser tomography (HRT) with the TLPG (IOP - ICP measured by LP), in 22 patients with high-pressure glaucoma (no washout), 13 with NTG (washed out for 1 months), and 17 with OHT [27]. It is unclear whether the glaucoma patients in this study were also used in the previous study by Ren et al. The OHT subjects were significantly younger than the glaucoma subjects $(p=0.02)$ but TLPG was not significantly associated with age. Neuroretinal rim area showed a trend towards an association with age in the left eye ( $p=0.57$ for right eye, $p=0.06$ for left eye). ICP was significantly higher in the OHT group $(16 \pm 3$ vs $11 \pm 3$ $\mathrm{mmHg}, p<0.001)$. A multivariate analysis using TLPG, ICP, and IOP as dependent parameters revealed the neuroretinal rim area was significantly associated with the TLPG ( $p=0.04$, unstandardised coefficient B: $-0.13 ; 95 \%$ CI -0.26 to -0.01$)$.

Berdahl et al. conducted two retrospective reviews of medical records from the Mayo Clinic. In the first of these they examined the records of 31,786 subjects who underwent LP (in the lateral decubitus position) between 1996 and 2007 [26]. A total of 28 patients with POAG and 49 controls were compared. All subjects had a documented eye examination including IOP and cup-to disc ratio, and had no medical conditions or medication known to affect ICP. Indications for LP were similar between both groups aside from headache (more common in control group, $p<0.05$ ), and radiculopathy (more common in POAG group, $p<$ $0.05)$. HTN was more common in the POAG group $(p<$ 0.05). Mean ICP was lower in the POAG group than the normal group $(9.2 \pm 2.9$ vs $13.0 \pm 4.2 \mathrm{mmHg} p<0.00005)$. Multivariate analysis showed that cup-to-disc ratio was associated with lower ICP $(p<0.0001)$, whereas headache as an indication for LP was associated with higher ICP $(p<$ 0.05); ICP was not associated with VF MD or HTN. As headache was associated with higher ICP, and headache was more common in the control group, this could have been a confounder.

Berdahl et al. then went on to examine a larger group of 62,468 subjects who had LP between 1985 and 2007 [65]. These included subjects from the previous study. Overall, 57 subjects with POAG, 11 with NTG, 27 with OHT, and 105 age-matched controls were analysed for a relationship between ICP and other variables. ICP was significantly lower in POAG compared with controls $(9.1 \pm 0.77$ vs $11.8 \pm 0.71 \mathrm{mmHg}, p<0.001)$ and NTG compared with controls $(8.7 \pm 1.16$ vs $11.8 \pm 0.71 \mathrm{mmHg}, p<0.01)$. ICP was higher in OHT than controls $(12.6 \pm 0.85$ vs $10.6 \pm$ $0.81, p<0.05)$. CSF protein concentration was significantly lower in the POAG than control groups (58.1 vs 68.1, $P<$ 0.05 ), as it was in NTG than control groups (45.5 vs 68.1, $p=0.01$ ). The mean TLPG (IOPmax - ICP) was significantly higher in POAG and NTG patients as compared with age-matched controls $(11.6 \pm 11.0 \mathrm{mmHg}$ vs $7.4 \pm 4.8 \mathrm{mmHg}$ vs $3.3 \pm 4.0 \mathrm{mmHg}, p<0.01)$. The TLPG was significantly higher in the OHT group vs age-matched controls $(11.5 \pm 5.1 \mathrm{mmHg}$ vs $5.2 \pm 3.8 \mathrm{mmHg}, p<0.05)$. The finding of a higher TLPG in OHT patients may have been primarily due to a high IOP in this group, but it suggests that a high TLPG is not always associated with glaucoma. Berdahl's group did not measure LC thickness, which would have affected the TLPG. Absolute values for BP were not analysed, although the prevalence of hypertension was not significantly different between groups and their controls $(p \leq 0.10)$. Multivariate analysis correcting for variables predictive of ICP (including headache) found POAG and NTG were independently associated with lower ICP, and OHT was associated with higher ICP.

This group of studies by Ren et al. and Berdahl et al. demonstrate a correlation between low ICP and glaucoma, and high ICP and OHT, when ICP is measured by LP. Absolute BP was not correlated with ICP, although BP was only measured by Ren et al., and nocturnal BP was not recorded. However, in their first study, Berdahl et al. found HTN was more common in the glaucoma subjects, suggesting that low BP was not responsible for low ICP in this group.

Non-invasive methods have also been used to examine the link between ICP and glaucoma. These studies are generally less convincing.

Wang et al. measured ONS width (ONSW, calculated as half the ONSD-half the optic nerve diameter) using MRI as a surrogate for orbital CSF pressure in 18 subjects with POAG, 21 with NTG, and 21 age-matched controls [25]. Subjects were not included if they had any medical history or were on any medication that could influence ICP. Systolic and diastolic BP was similar across groups. The ONSW was less in the NTG group than the POAG and control groups at 3,9 , and $15 \mathrm{~mm}$ behind the globe $(p=$ 0.002). ONSW was not significantly different between POAG and control groups. This differs from the previously mentioned study by Cennamo et al., which found that ONS diameter measured by US was significantly lower in 53 eyes of patients with POAG as compared with 64 normal control eyes [44]. Pinto et al. compared ONSD measurement using US at $3 \mathrm{~mm}$ behind the globe in 46 patients with NTG, 61 with POAG, and 42 controls from cataract clinics [66]. In contrast to the two previously mentioned studies, they found no significant difference in ONSD between groups.

Siaudvytyte et al. correlated ICP measured using twodepth Transcranial Doppler with neuroretinal rim area and retrobulbar blood flow in 40 patients with NTG [67]. Lower ICP was correlated with decreased neuroretinal rim area on confocal laser scanning tomography $(r=0.51, p=0.001)$. Patients with ICP $<8.3 \mathrm{mmHg}$ had significantly lower 
ophthalmic artery blood flow velocities than those with ICP $>8.3 \mathrm{mmHg}(p<0.04)$. This study suggests that low ICP is associated with nerve damage in NTG, but also suggests that low ICP may be linked to poor blood supply at the nerve head. However, it is not yet conclusively shown whether ICP can be accurately measured using Transcranial Doppler as used in this study.

Lee et al. used a previously established formula to estimate ICP in 12,743 Koreans who participated in the Korean National Health and Nutrition Examination Survey [68]. $\mathrm{ICP}$ in $\mathrm{mmHg}$ was estimated as $=0.5 \times \mathrm{BMI}+0.16 \times$ diastolic BP $-(0.18 \times$ age in years $)-1.91[69,70]$. TLPG was calculated as IOP - ICP. A total of 12,069 controls without glaucoma were compared with 674 NTG subjects. The NTG subjects were significantly older than controls $(p<$ $0.001)$ and had a higher prevalence of HTN $(P<0.001)$. Estimated ICP and TLPG were significantly different between control and NTG groups (ICP $11.69 \pm 0.04$ vs $10.76 \pm 0.16 \mathrm{mmHg}, \quad P<0.001 ; \quad$ TLPG $2.31 \pm 0.06$ vs $3.82 \pm 0.21 \mathrm{mmHg}, p<0.001)$. This again suggests ICP is lower in NTG and although (according to the formula), a higher diastolic BP should give a higher ICP, ICP was lower in NTG patients, while the prevalence of HTN was higher. Although the NTG group was older, HTN was still significantly associated with NTG patients with IOP $<15 \mathrm{mmHg}$ when adjusted for age and smoking status $(p<0.001)$.

Jonas et al. used a similar formula to calculate ICP and combined this with IOP measured in 4546 subjects in the Central India Eye and Medical Study to estimate the TLPG [71]. Patients with glaucoma were categorised as such based on a glaucomatous appearance of the optic disc. The glaucomatous group had a significantly higher IOP than the non-glaucomatous group $(17.2 \mathrm{mmHg}$ vs $13.7 \mathrm{mmHg}, p<$ $0.001)$, a lower estimated ICP $(7.6 \pm 3.8 \mathrm{mmHg}$ vs $10.0 \pm$ $3.6 \mathrm{mmHg}, p<0.001)$, and a higher TLPG $(9.8 \pm 8.2 \mathrm{mmHg}$ vs $3.6 \pm 4.2 \mathrm{mmHg}, p<0.001)$. An obvious criticism of papers that correlate formulas like this with glaucoma, is that age and BP are included in the formula, and these are independent risk factors for glaucoma, regardless of ICP.

Some work has challenged the link between ICP and glaucoma. Loiselle et al. measured ICP non-invasively using distortion product otoacoustic emission (DPOAE) phase and body position in 30 controls, 17 subjects with POAG, and 15 with NTG [72]. They found no evidence that glaucoma subjects had a reduced ICP. However, nine patients were removed from the between test comparisons and this method is not a robust means of detecting ICP, especially in such a small group. A separate study found that DPOAE only changed significantly with large $(\geq 15 \mathrm{mmHg}$ ) changes in ICP: therefore DPOAE would not detect the small differences in ICP between patients with glaucoma and controls [73].
Linden et al. compared ICP and TLPG in 13 NTG patients with 11 controls using LP and applanation resonance tonometry measured both supine and sitting, with previously published reference data from a larger control group (40 subjects) used for a comparison for ICP in the supine position [74]. They did not find a significant difference between ICP in NTG and control groups in any body position. The NTG group in this study was small $(n=$ 13), as was the initial control group (11). Had they not used extra controls from a different study this would have been underpowered to detect a significant difference, and controls from another study may not be directly comparable. Furthermore, if NTG is a multifactorial condition where in some patients other factors such as optic nerve head blood supply contribute more than ICP, a small group is unlikely to detect a significantly lower ICP.

Pircher et al. carried out a small retrospective review of 38 patients who had progressive NTG and had undergone LP during CT cisternography [75]. TLPG was calculated as IOP - ICP. TLPG was compared with VF MD. Mean opening ICP was $11.6 \pm 3.7 \mathrm{mmHg}$. They found no significant correlation between TLPG and MD. However, no power calculation was performed, and in right eyes they did find a trend between raised TLPG and MD $(\rho=0.22, p=$ 0.23 ). Indeed, they would have been unlikely to have found a significant correlation between IOP and MD, although this was not assessed. Furthermore, these were all patients in whom optic nerve sheath compartment syndrome was suspected, and therefore may have had a condition that would have confounded results. They did not compare the TLPG with a control group.

Finally, Igarashi et al. used LP to measure ICP in 20 idiopathic NPH patients (11 with NTG with 9 without) [76]. They found ICP was significantly higher in the NTG group $(10.8 \pm 2.9$ vs $8.3 \pm 1.4 \mathrm{mmHg}, p<0.005)$. Although interesting, this was a small study and patients with NPH (with reduced CSF turnover) may not be representative of the larger population.

\section{Does reducing ICP cause glaucomatous optic neuropathy?}

Studies that suggest low ICP is a causative factor in glaucoma, not simply a correlated finding, include those where ICP has been reduced and this has subsequently induced glaucomatous optic nerve changes. Gallina et al. reported that NPH patients who receive ventriculoperitoneal (VP) shunts (which can significantly lower ICP), have a significantly increased risk of NTG compared with the general population (9/22 or $41 \%$ of patients) [77]. Twenty-two patients with NPH who had received VP shunt surgery at least 6 months earlier were screened for NTG. A total of 9/ 
22 patients were diagnosed with NTG and had an average vertical cup-to disc ratio of 0.69 vs 0.54 in the non-NTG group $(p<0.001)$. The median opening shunt valve pressure in the patients with NTG was $6.6 \mathrm{mmHg}$, and in the nonNTG group was $8.1 \mathrm{mmHg}$. This suggests that patients with lower pressure valve settings were more likely to be diagnosed with NTG, although unfortunately the paper gives no $p$-value for the difference in mean opening pressure between these groups. Patients with NTG had their shunt fitted an average of 5.3 years previously, whereas those without NTG had it fitted an average of 3.4 years earlier. This fits with the hypothesis that a lower ICP causes glaucomatous nerve damage that increases over time. One criticism of this paper regards its diagnostic criteria for NTG. NTG was diagnosed in patients with an IOP $<21 \mathrm{mmHg}$, $\mathrm{CCT} \geq 520 \mu \mathrm{m}$, cup-to-disc ratio $>0.5$ in association with $\mathrm{MD} \leq 2 \mathrm{~dB}$ and PSD $>2 \mathrm{~dB}$. OCT and optic nerve head pictures were independently evaluated by an ophthalmologist to assess concordance (figures for concordance not given). Ideally, they should have compared the prevalence of NTG using their diagnostic criteria in an age-matched control group who had not been shunted, or used a more robust definition of NTG. Furthermore, the prevalence of glaucoma may be higher in all patients with NPH. Chang et al. found a glaucoma prevalence of $18.1 \%$ in this group (compared with $2-3 \%$ in the general population), using a retrospective review of case notes [49]. However, many of these patients had been shunted, and the paper does not state whether glaucoma prevalence was $18.1 \%$ before shunt placement.

Yablonski et al. examined the TLPG in cats by reducing ICP and lowering IOP in one eye [78]. Optic nerves were examined histologically after 3 weeks. Eyes with unchanged IOP and lowered ICP revealed cupping and posterior displacement of the LC. Eyes with lowered IOP and less significant changes in TLPG did not show these glaucomatous changes. Yang et al. inserted a lumbarperitoneal shunt in four monkeys to reduce ICP, and compared these with five control monkeys, who had a closed shunt inserted [79]. ICP was significantly different between the intervention and control groups $(2.0 \pm 0.8$ vs. $8.2 \pm 2.6 \mathrm{mmHg}$ at 6 months; $P<0.001$ ). Monkeys were followed up with disc OCTs and photographs for 1 year. Retinal nerve fibre layer thickness was similar at baseline but significantly less in the intervention than control groups at 1 year $(89.4 \pm 15.0$ vs. $100.9 \pm 7.4 \mu \mathrm{m} ; p<0.05)$. One monkey in the intervention group developed a disc haemorrhage.

Zhao et al. examined the effect of varying IOP and ICP on the full field electroretinogram (ERG) in rat eyes [80]. A cannula was placed in the vitreous of live rat eyes and IOP varied using saline solution. ICP was varied and measured using a cannula placed in the lateral ventricle. Above an
IOP of $50 \mathrm{mmHg}$, both STR (ganglion/amacrine cell function) and b-wave (bipolar cell function) amplitudes decreased; this effect was more pronounced when ICP was reduced (to $-5 \mathrm{mmHg}$ ), and less pronounced when increased (to $15 \mathrm{mmHg}$ ).

These observational studies suggest that reducing ICP induces glaucomatous optic nerve changes in patients with $\mathrm{NPH}$, cats and monkeys, and reduces retinal function in rats.

\section{Methods of measuring ICP}

ICP can be measured directly using LP, however it is important to bear in mind that ICP varies with body position, and therefore most figures for ICP measured by LP will relate to a recumbent posture, as LP is usually measured in the lateral decubitus position, with the patient lying on one side. Continuous monitoring can be performed using intracranial catheters or micotransducers.

ONSD (measured using ultrasound, CT or MRI) has been used as a surrogate measure for ICP. If this is a reliable means of measuring ICP, it suggests ICP is transmitted to the ONS [41-43, 81]. Other methods include ophthalmodynamometry (measuring venous outflow pressure of the central retinal vein), tympanic membrane displacement, and two-depth transcranial doppler (measurement of blood flow velocities in the intra- and extra-cranial segments of the ophthalmic artery).

Chen et al. measured ONSD $3 \mathrm{~mm}$ posterior to the globe in 84 patients using US prior to and following LP [42]. US findings were significantly associated with LP $(p<0.01)$. Bäuerle et al. found that US measurement of ONSD correlates well with MRI and is reliable at $3 \mathrm{~mm}$ behind the globe but not at $5 \mathrm{~mm}$ [81].

Watanabe et al. measured ONSD before and after surgery using T2-weighted MRI in 12 patients who underwent craniostomy for subdural haematoma [43]. ONSD was significantly correlated with manometer measured subdural pressure $(r=0.879, p=0.0036)$.

In contrast to the above studies, Kavi et al. did not find a correlation between ONSD measured using CT and invasively measured ICP in 68 patients with intracranial injuries [82]. However, most patients had presented with raised ICP which had been reduced medically prior to CT scan, and nerve sheath expansions may change after treatment.

The majority of studies show a correlation between ONSD and ICP, suggesting ICP is transmitted to the optic nerve sheath. Two studies found lower ONSDs in patients with NTG and POAG compared with controls, suggesting lower ICP in these groups [25, 44]. Conversely one study found no difference [66]. 


\section{Confounding factors-the role of blood pressure}

Studies have linked hypotension to NTG, and suggested that corresponding poor blood supply to the optic nerve head may cause damage. Hypotension is associated both with reduced ICP and with reduced IOP [23, 68]. If the association of glaucoma with low ICP can be explained through hypotension, then hypotension should be as significantly linked with glaucoma as ICP, though the picture is clouded by the diurnal variation in BP and ICP. Equally, BP should be shown to influence the TLPG.

Various studies have shown that increasing systolic or diastolic BP by $10 \mathrm{mmHg}$ is associated with a $0.2-0.85$ $\mathrm{mmHg}$ increase in IOP [23, 83, 84]. This suggests hypertension is unlikely to be associated with significant increases in IOP. Studies have linked both hypertension and hypotension with glaucoma. In the Blue Mountains Eye Study $(n=3654)$, hypertension was significantly associated with POAG, independently of the effect of BP on IOP [84]. Conversely, in African-descendent participants of the Barbados Eye Studies $(n=3222)$, the relative risk of POAG was reduced with higher BP [85].

Perhaps anti-hypertensive treatment increases glaucoma risk. A regression analysis in the Thessaloniki Eye Study $(n=232)$ found that cup area and cup-to-disk ratio were increased in patients with a diastolic $\mathrm{BP}<90 \mathrm{mmHg}$ as a result of anti-hypertensive treatment, as compared with those with a diastolic $\mathrm{BP}<90 \mathrm{mmHg}$ without treatment or a diastolic BP $>90 \mathrm{mmHg}$ [86].

Hayreh et al. carried out ambulatory BP monitoring in patients with NTG $(n=67)$, POAG $(n=21)$, and anterior ischaemic optic neuropathy (AION) $(n=53)$ and found a significantly $(p=0.003)$ lower nighttime mean diastolic BP and significantly higher $(p=0.004)$ greater mean percentage drop in diastolic BP in NTG than in AION patients [87]. Unfortunately, there was no normal control group in this study, and BP in AION patients is unlikely to be representative of normal subjects.

Yilmaz et al. performed ambulatory BP testing on 35 glaucoma patients and 40 controls [88]. Mean daytime systolic BP of glaucoma patients was significantly lower than controls $(p=0.008)$. Nighttime systolic BP was also significantly lower $(p=0.001)$. Night and daytime systolic BP were risk factors for developing glaucoma in multiple regression analysis.

Graham et al. performed ambulatory BP monitoring in 84 glaucoma patients [89]. No significant differences in BP dips or mean day or nighttime $\mathrm{BP}$ values were found between NTG and POAG groups. A total of 52 patients who had been followed for more than 2 years and had at least six reliable fields were categorised according to progression $(n=37)$ or stability $(n=15)$. No differences were found between daytime BP measurements. However, at night, BP was significantly lower in the group showing progression.

Ren et al. found that the TLPG was not significantly associated with $\operatorname{BP}(p=0.97)$ [13]. They did, however, find that ICP was significantly correlated with systolic and mean BP in their control group $(p=0.04)$, but not in the NTG or POAG groups. The formula used by Lee et al. suggests that raising diastolic BP raises ICP [68].

$\mathrm{He}$ et al. examined ERG responses to IOP in live rats as BP was varied pharmacologically [90]. STR and b-wave amplitudes were significantly reduced when IOP was increased above $40 \mathrm{mmHg}$ as mean arterial pressure was reduced from 161 to 100 to $63 \mathrm{mmHg}$ (interaction $p<$ 0.001, two-way RM ANOVA). This suggests that lower mean arterial pressures increase the susceptibility of rat ganglion, amacrine, and bipolar cells to increasing IOP.

The evidence relating to $\mathrm{BP}$ and glaucoma is mixed and complex. Although hypotension may increase glaucomatous nerve damage, this does not necessarily explain the effect of reduced ICP on the nerve head. Nocturnal hypotension may cause lower nocturnal ICP, and this is the period during which differing ICP is likely to play the greatest role on stress at the LC (due to the ICP drop on standing and maintenance at $\sim 3 \mathrm{mmHg}$ secondary to orbital pressure). However, studies associating ICP with glaucoma and NTG did not measure ICP at night, so nocturnal dips in BP are unlikely to be responsible for the low ICP in these patients. Of the two major works correlating glaucoma with ICP, Ren et al. found that BP was only associated with ICP in the control group, but not in groups with NTG or POAG, and Berdahl et al. did not comment on BP [13, 65]. As studies give conflicting results regarding the role of daytime $\mathrm{BP}$ in glaucoma, and experimental studies suggest lowering ICP independent of $\mathrm{BP}$ can produce glaucomatous nerve damage, it is unlikely that the association between low daytime ICP and glaucoma is due to low BP.

\section{Implications for glaucoma management}

If a high TLPG contributes to glaucomatous optic neuropathy, this could be reduced by decreasing IOP, increasing LC thickness, or increasing ICP. We know reducing IOP slows VF progression in glaucoma, but we do not currently employ strategies to increase ICP [3]. Lifestyle advice could include advising patients with NTG to sleep with only a thin pillow. Caution could be exercised in the use of carbonic anhydrase inhibitors, as they reduce ICP.

Pharmacological agents which could be used to increase ICP include vitamin A, caffeine, theophylline, and tetracyclines, though caffeine may also increase IOP [91]. 
Han et al. fed drinking water containing caffeine equivalent to the standard daily consumption in humans to rats for 3 weeks, and found a significant increase in lateral ventricle size in $40 \%$ [92]. Cross sectional area of lateral ventricles doubled in treated rats as compared with control rats. Doubling the caffeine dose did not cause a further significant increase in ventricle size. Plasma concentration of caffeine in the $40 \%$ of treated rats with ventriculomegaly was three times higher than in treated rats without ventriculomegaly. Caffeine-treated rats demonstrated a significant increase in the production of CSF compared with control rats $(5.02 \pm 0.15$ versus $2.95 \pm 0.12 \mu \mathrm{l} / \mathrm{min}, p<$ $0.01)$. There was a significant increase in expression of the $\mathrm{Na}^{+} / \mathrm{K}^{+}$-ATPase in the choroid plexus of caffeine-treated rats, and a significant increase in cerebral blood flow as compared with control rats. Ten rats treated with a one-off dose of caffeine showed a significantly reduced production of CSF, suggesting an effect inversion in the acute effects of caffeine. Caffeine and theophylline (a metabolite of caffeine) were shown to be effective for low pressure (postdural puncture) headaches in a Cochrane review [93]. The mechanism of action may be increased CSF production.

Vitamin A has been proposed as a causal factor in $\mathrm{IIH}$, through an increase in intracranial pressure [94, 95]. Fraunfelder et al. retrospectively reviewed 1950 case reports of ocular side effects from isotretinoin on spontaneous reporting systems [94]. They found 179 reports of intracranial hypertension in patients on isotretinoin. The mean time between starting treatment and development of raised ICP was 2.3 months. Overall, $48 \%$ of cases reported follow up, and ICP reduced to normal within a few months in all after stopping the isotretinoin. Six cases were re-challenged with isotretinoin and re-developed raised ICP. Botton et al. report on 31 children treated with all-trans-retinoic-acid and chemotherapy for acute promyelocytic leukaemia [95]. Overall, 16\% developed signs of IIH.

Jacobson et al. measured serum retinol concentrations in 16 women with IIH and 70 controls [96]. They found significantly higher levels in the IIH group $(752$ vs $530 \mathrm{ug} / \mathrm{L}$, $p<0.001)$. A similar study by Tabassi et al. comparing 20 IIH patients with 20 controls found higher CSF concentrations of retinol in IIH (576 vs $63 \mathrm{nM}, p<0.05$ ), but only a trend towards higher serum retinol concentrations in $\mathrm{IIH}$ (1003 vs $897 \mathrm{nM}, p=0.1$ ) [97].

IIH has been reported after tetracycline use [98-100]. Friedman et al. report on six patients who developed IIH during doxycycline therapy, which resolved on stopping treatment [98]. Gardner et al. review 37 patients with IIH associated with tetracycline usage [99]. A total of 26/37 had resolution of IIH on stopping the drug, and 4/37 had recurrence on re-starting tetracycline. Chiu et al. reviewed the notes of 12 patients who developed IIH after starting minocycline [100]. Nine developed IIH within 8 weeks of starting treatment. None of the patients developed recurrences of IIH within 1 year of stopping treatment.

While multiple agents may raise ICP, a treatment for glaucoma would need to be safe to use for long periods of time, and therefore caffeine, theophylline and vitamin A are the most likely candidates.

\section{Conclusions}

The formulae for calculating stress within the LC predict that stress on the optic nerve is dependent on ICP in addition to IOP, though likely to a lesser extent, (a higher TLPG causing greater stress). If this is true, patients with POAG and NTG should generally have low ICP, and patients with OHT high ICP. The most reliable studies performed to date have confirmed these associations [13, 26, 27, 65]. Studies suggesting otherwise have been underpowered or have not measured ICP using LP [72, 74-76]. Furthermore, if this is true, patients with glaucoma should tend to have a thinner LC with a greater diameter, which is displaced away from the globe [18, 19, 52, 53]. Effective treatment should reverse LC displacement [59]. Equally, changes in ICP should affect LC displacement [61, 62]. Optic nerve damage should occur more significantly at thinner areas of the LC $[52,53]$. Patients and animals having low ICP artificially induced independently of BP (such as via placement of CSF shunts) should be more prone to developing glaucomatous nerve damage [77-80].

In our review we find that the majority of research supports these facts and, taken together, the evidence suggesting that low ICP plays some role in the pathology of glaucoma is convincing. Further studies looking at glaucomatous changes in patients with low ICP (such as those with CSF shunts) would be helpful. If NPH patients with low ICP could be shown to develop significant thinning of the neuroretinal rim as compared with NPH patients with a normal ICP, this would support the theory that ICP and not simply changes in CSF composition in these diseases, plays an important role in the pathogenesis of glaucoma.

We can look ahead to an observational study to examine the effect of caffeine, theophylline or vitamin A on ICP in humans, and a randomised controlled trial to analyse the effect of one of these agents on progression in NTG.

\section{Compliance with ethical standards}

Conflict of interest The authors declare that they have no conflict of interest.

Publisher's note Springer Nature remains neutral with regard to jurisdictional claims in published maps and institutional affiliations. 


\section{References}

1. Leske MC. Open-angle glaucoma-an epidemiologic overview. Ophthalmic Epidemiol. 2007;14:166-72.

2. Anderson DR. Normal tension glaucoma study Collaborative normal tension glaucoma study. Curr Opin Ophthalmol. 2003;14:86-90.

3. Garway-Heath DF, Crabb DP, Bunce C, Lascaratos G, Amalfitano F, Anand N, et al. Latanoprost for open-angle glaucoma (UKGTS): a randomised, multicentre, placebo-controlled trial. Lancet. 2015;385:1295-304.

4. Sommer A, Tielsch JM, Katz J, Quigley HA, Gottsch JD, Javitt $\mathrm{J}$, et al. Relationship between intraocular pressure and primary open angle glaucoma among white and black Americans. The Baltimore Eye Survey. Arch Ophthalmol. 1991;109:1090-5.

5. Iwase A, Suzuki Y, Araie M, Yamamoto T, Abe H, Shirato S, et al. The prevalence of primary open-angle glaucoma in Japanese. Ophthalmology. 2004;111:1641-8.

6. Kass MA, Heuer DK, Higginbotham EJ, Johnson CA, Keltner JL, Miller JP, et al. The Ocular Hypertension Treatment Study: a randomized trial determines that topical ocular hypotensive medication delays or prevents the onset of primary open-angle glaucoma. Arch Ophthalmol. 2002;120:701-13.

7. Drance SM, Sweeney VP, Morgan RW, Feldman F. Studies of factors involved in the production of low tension glaucoma. Arch Ophthalmol. 1973;89:457-65.

8. Flammer J, Orgül S, Costa VP, Orzalesi N, Krieglstein GK, Serra LM, et al. The impact of ocular blood flow in glaucoma. Prog Retin Eye Res. 2002;21:359-93.

9. Killer HE, Jaggi GP, Flammer J, Miller NR. Is open-angle glaucoma caused by impaired cerebrospinal fluid circulation: around the optic nerve? Clin Exp Ophthalmol. 2008;36:308-11.

10. Hammam T, Montgomery D, Morris D, Imrie F. Prevalence of serum autoantibodies and paraproteins in patients with glaucoma. Eye. 2008;22:349-53.

11. Sigal IA, Flanagan JG, Tertinegg I, Ethier CR. Predicted extension, compression and shearing of optic nerve head tissues. Exp Eye Res. 2007;85:312-22.

12. Wang YX, Xu L, Wei WBin, Jonas JB. Intraocular pressure and its normal range adjusted for ocular and systemic parameters. The Beijing Eye Study 2011. PLoS ONE Public Libr Sci. 2018;13:e0196926.

13. Ren R, Jonas JB, Tian G, Zhen Y, Ma K, Li S, et al. Cerebrospinal fluid pressure in glaucoma. Ophthalmology. 2010;117:259-66.

14. Magnaes B. Body position and cerebrospinal fluid pressure. J Neurosurg. 1976;44:698-705.

15. Jain MR, Marmion VJ. Rapid pneumatic and Mackey-Marg applanation tonometry to evaluate the postural effect on intraocular pressure. Br J Ophthalmol. 1976;60:687-93.

16. Morgan WH, Balaratnasingam C, Lind CRP, Colley S, Kang $\mathrm{MH}$, House $\mathrm{PH}$, et al. Cerebrospinal fluid pressure and the eye. Br J Ophthalmol. 2016;100:71-7.

17. Hayreh SS. Cerebrospinal fluid pressure and glaucomatous optic disc cupping. Graefe's Arch Clin Exp Ophthalmol. 2009;247:721-4.

18. Li L, Bian A, Cheng G, Zhou Q. Posterior displacement of the lamina cribrosa in normal-tension and high-tension glaucoma. Acta Ophthalmol. 2016;94:e492-500.

19. Kim YW, Kim DW, Jeoung JW, Kim DM, Park KH. Peripheral lamina cribrosa depth in primary open-angle glaucoma: a sweptsource optical coherence tomography study of lamina cribrosa. Eye. 2015;29:1368-74.

20. Wells AP, Garway-Heath DF, Poostchi A, Wong T, Chan KCY, Sachdev N. Corneal Hysteresis but not corneal thickness correlates with optic nerve surface compliance in glaucoma patients. Investig Opthalmology Vis Sci. 2008;49:3262.

21. Digre KB, Nakamoto BK, Warner JEA, Langeberg WJ, Baggaley SK, Katz BJ. A comparison of idiopathic intracranial hypertension with and without papilledema. Headache NIH Public Access. 2009;49:185-93.

22. Killer HE, Laeng HR, Flammer J, Groscurth P. Architecture of arachnoid trabeculae, pillars, and septa in the subarachnoid space of the human optic nerve: anatomy and clinical considerations. Br J Ophthalmol. 2003;87:777-81.

23. Costa VP, Arcieri ES, Harris A. Blood pressure and glaucoma. Br J Ophthalmol. 2009;93:1276-82.

24. Fleischman D, Bicket AK, Stinnett SS, Berdahl JP, Jonas JB, Wang NL, et al. Analysis of cerebrospinal fluid pressure estimation using formulae derived from clinical data. Investig Opthalmology Vis Sci Assoc Res Vis Ophthalmol. 2016;57:5625.

25. Wang N, Xie X, Yang D, Xian J, Li Y, Ren R, et al. Orbital cerebrospinal fluid space in glaucoma: the Beijing Intracranial and Intraocular Pressure (iCOP) Study. Ophthalmology. 2012;119:2065-2073.e1.

26. Berdahl JP, Allingham RR, Johnson DH. Cerebrospinal fluid pressure is decreased in primary open-angle glaucoma. Ophthalmology. 2008;115:763-8.

27. Ren R, Wang N, Zhang X, Cui T, Jonas JB. Trans-lamina cribrosa pressure difference correlated with neuroretinal rim area in glaucoma. Graefe's Arch Clin Exp Ophthalmol. 2011;249:1057-63.

28. Downs JC, Roberts MD, Burgoyne CF. Mechanical environment of the optic nerve head in glaucoma. Optom Vis Sci. 2008;85: E425-35.

29. Young W, Budynas R, Sadegh A, Roark R. Roark's formulas for stress and strain. 8th ed. Blackwell's, New York; 2012.

30. Feola AJ, Myers JG, Raykin J, Mulugeta L, Nelson ES, Samuels $\mathrm{BC}$, et al. Finite element modeling of factors influencing optic nerve head deformation due to intracranial pressure. Investig Opthalmology Vis Sci. 2016;57:1901.

31. Hua Y, Voorhees AP, Sigal IA. Cerebrospinal fluid pressure: revisiting factors influencing optic nerve head biomechanics. Investig Opthalmology Vis Sci. 2018;59:154.

32. Tong J, Ghate D, Kedar S, Gu L. Relative contributions of intracranial pressure and intraocular pressure on lamina cribrosa behavior. J Ophthalmol. 2019;2019:1-8.

33. Hou R, Zhang Z, Yang D, Wang H, Chen W, Li Z, et al. Intracranial pressure (ICP) and optic nerve subarachnoid space pressure (ONSP) correlation in the optic nerve chamber: the Beijing Intracranial and Intraocular Pressure (iCOP) study. Brain Res. 2016;1635:201-8.

34. Morgan WH, Yu DY, Alder VA, Cringle SJ, Cooper RL, House $\mathrm{PH}$, et al. The correlation between cerebrospinal fluid pressure and retrolaminar tissue pressure. Invest Ophthalmol Vis Sci. 1998;39:1419-28.

35. Bidot S, Bruce BB, Saindane AM, Newman NJ, Biousse V. Asymmetric papilledema in idiopathic intracranial hypertension. J Neuro-Ophthalmol. 2015;35:31-6.

36. Bidot S, Clough L, Saindane AM, Newman NJ, Biousse V, Bruce BB. The optic canal size is associated with the severity of papilledema and poor visual function in idiopathic intracranial hypertension. J Neuro-Ophthalmol. 2016;36:120-5.

37. Mathieu E, Gupta N, Paczka-Giorgi LA, Zhou X, Ahari A, Lani $\mathrm{R}$, et al. Reduced cerebrospinal fluid inflow to the optic nerve in glaucoma. Investig Opthalmology Vis Sci. 2018;59:5876.

38. Killer HE, Miller NR, Flammer J, Meyer P, Weinreb RN, Remonda L, et al. Cerebrospinal fluid exchange in the optic nerve in normal-tension glaucoma. $\mathrm{Br} \mathrm{J}$ Ophthalmol. 2012;96:544-8 
39. Jaggi GP, Mironov A, Huber AR, Killer HE. Optic nerve compartment syndrome in a patient with optic nerve sheath meningioma. Eur J Ophthalmol. 2007;17:454-8.

40. Plog BA, Nedergaard M. The glymphatic system in central nervous system health and disease: past, present, and future. Annu Rev Pathol NIH Public Access. 2018;13:379-94.

41. Geeraerts T, Newcombe VF, Coles JP, Abate M, Perkes IE, Hutchinson PJ, et al. Use of T2-weighted magnetic resonance imaging of the optic nerve sheath to detect raised intracranial pressure. Crit Care. 2008;12:R114.

42. Chen L, Wang L, Hu Y, Jiang X, Wang Y, Xing Y. Ultrasonic measurement of optic nerve sheath diameter: a non-invasive surrogate approach for dynamic, real-time evaluation of intracranial pressure. $\mathrm{Br} \mathrm{J}$ Ophthalmol BMJ Publ Group Ltd. 2019;103:437-41.

43. Watanabe A, Kinouchi H, Horikoshi T, Uchida M, Ishigame K. Effect of intracranial pressure on the diameter of the optic nerve sheath. J Neurosurg. 2008;109:255-8.

44. Cennamo G, Montorio D, Breve MA, Brescia Morra V, Menna F, Cennamo G. Evaluation of optic nerve subarachnoid space in primary open angle glaucoma using ultrasound examination. PLoS ONE. 2018;13:e0208064.

45. Pircher A, Montali M, Berberat J, Remonda L, Killer HE. Relationship between the optic nerve sheath diameter and lumbar cerebrospinal fluid pressure in patients with normal tension glaucoma. Eye. 2017;31:1365-72.

46. Serot J-M, Zmudka J, Jouanny P. A possible role for csf turnover and choroid plexus in the pathogenesis of late onset Alzheimer's disease. J Alzheimer's Dis. 2012;30:17-26.

47. Preston JE. Ageing choroid plexus-cerebrospinal fluid system. Microsc Res Tech. 2001;52:31-7.

48. Tamura H, Kawakami H, Kanamoto T, Kato T, Yokoyama T, Sasaki K, et al. High frequency of open-angle glaucoma in Japanese patients with Alzheimer's disease. J Neurol Sci. 2006;246:79-83.

49. Chang TC, Singh K. Glaucomatous disease in patients with normal pressure hydrocephalus. J Glaucoma. 2009;18:243-6.

50. Kessing LV, Lopez AG, Andersen PK, Kessing SV. No increased risk of developing alzheimer disease in patients with glaucoma. J Glaucoma. 2007;16:47-51.

51. Yoneda S, Hara H, Hirata A, Fukushima M, Inomata Y, Tanihara $\mathrm{H}$. Vitreous fluid levels of $\beta$-amyloid(1-42) and tau in patients with retinal diseases. Jpn J Ophthalmol. 2005;49:106-8.

52. Park H-YL, Jeon SH, Park CK. Enhanced depth imaging detects lamina cribrosa thickness differences in normal tension glaucoma and primary open-angle glaucoma. Ophthalmology. 2012; 119:10-20.

53. Kwun Y, Han JC, Kee C. Comparison of lamina cribrosa thickness in normal tension glaucoma patients with unilateral visual field defect. Am J Ophthalmol. 2015;159:512-518.e1.

54. Jonas JB, Berenshtein E, Holbach L. Lamina cribrosa thickness and spatial relationships between intraocular space and cerebrospinal fluid space in highly myopic eyes. Investig Opthalmology Vis Sci. 2004;45:2660.

55. Bae SH, Kang SH, Feng CS, Park J, Jeong JH, Yi K. Influence of myopia on size of optic nerve head and retinal nerve fiber layer thickness measured by spectral domain optical coherence tomography. Korean J Ophthalmol Korean Ophthalmological Soc. 2016;30:335-43.

56. Girkin CA, Fazio MA, Yang H, Reynaud J, Burgoyne CF, Smith $\mathrm{B}$, et al. Variation in the three-dimensional histomorphometry of the normal human optic nerve head with age and race: lamina cribrosa and peripapillary scleral thickness and position. Invest Ophthalmol Vis Sci Assoc Res Vis Ophthalmol. 2017;58: 3759-69.
57. Gordon MO, Beiser JA, Brandt JD, Heuer DK, Higginbotham EJ, Johnson CA, et al. The Ocular Hypertension Treatment Study: baseline factors that predict the onset of primary openangle glaucoma. Arch Ophthalmol (Chic, Ill 1960). 2002; 120:714-20. discussion 829-30.

58. Marcus MW, de Vries MM, Montolio FGJ, Jansonius NM. Myopia as a risk factor for open-angle glaucoma: a systematic review and meta-analysis. Ophthalmology. 2011;118:1989-1994.e2.

59. Lee EJ, Kim T-W, Weinreb RN, Kim H. Reversal of lamina cribrosa displacement after intraocular pressure reduction in open-angle glaucoma. Ophthalmology. 2013;120:553-9.

60. Yan DB, Coloma FM, Metheetrairut A, Trope GE, Heathcote JG, Ethier CR. Deformation of the lamina cribrosa by elevated intraocular pressure. Br J Ophthalmol. 1994;78:643-8.

61. Perez-Lopez M, Ting DSJ, Clarke L. Lamina cribrosa displacement after optic nerve sheath fenestration in idiopathic intracranial hypertension: a new tool for monitoring changes in intracranial pressure? Br J Ophthalmol. 2014;98:1603-4.

62. Morgan WH, Chauhan BC, Yu D-Y, Cringle SJ, Alder VA, House PH. Optic disc movement with variations in intraocular and cerebrospinal fluid pressure. Investig Ophthalmol Vis Sci. 2002; 43:3236-42.

63. Jonas JB, Holbach L. Central corneal thickness and thickness of the lamina cribrosa in human eyes. Investig Opthalmology Vis Sci. 2005;46:1275.

64. Sigal IA. Interactions between geometry and mechanical properties on the optic nerve head. Investig Opthalmology Vis Sci. 2009;50:2785.

65. Berdahl JP, Fautsch MP, Stinnett SS, Allingham RR. Intracranial pressure in primary open angle glaucoma, normal tension glaucoma, and ocular hypertension: a case-control study. Investig Opthalmology Vis Sci. 2008;49:5412.

66. Abegão Pinto L, Vandewalle E, Pronk A, Stalmans I. Intraocular pressure correlates with optic nerve sheath diameter in patients with normal tension glaucoma. Graefes Arch Clin Exp Ophthalmol. 2012;250:1075-80.

67. Siaudvytyte L, Januleviciene I, Daveckaite A, Ragauskas A, Siesky B, Harris A. Neuroretinal rim area and ocular haemodynamic parameters in patients with normal-tension glaucoma with differing intracranial pressures. Br J Ophthalmol. 2016;100:1134-8.

68. Lee SH, Kwak SW, Kang EM, Kim GA, Lee SY, Bae HW, et al. Estimated trans-lamina cribrosa pressure differences in low-teen and high-teen intraocular pressure normal tension glaucoma: the Korean National Health and Nutrition Examination Survey. PLoS ONE. 2016;11:e0148412.

69. Wang YX, Jonas JB, Wang NX, You QS, Yang D. Intraocular pressure and estimated cerebrospinal fluid pressure. the Beijing Eye Study. PLoS ONE. 2014;9:104267.

70. Xie X, Zhang X, Fu J, Wang H, Jonas JB, Peng X, et al. Noninvasive intracranial pressure estimation by orbital subarachnoid space measurement: the Beijing Intracranial and Intraocular Pressure (iCOP) study. Crit Care. 2013;17:R162.

71. Jonas JB, Nangia V, Wang N, Bhate K, Nangia P, Nangia P, et al. Trans-lamina cribrosa pressure difference and open-angle glaucoma. The Central India Eye and Medical Study. PLoS ONE. 2013;8:e82284.

72. Loiselle AR, de Kleine E, van Dijk P, Jansonius NM. Noninvasive intracranial pressure assessment using otoacoustic emissions: an application in glaucoma. PLoS ONE. 2018;13:e0204939.

73. Bershad EM, Urfy MZ, Pechacek A, McGrath M, Calvillo E, Horton $\mathrm{NJ}$, et al. Intracranial pressure modulates distortion product otoacoustic emissions. Neurosurgery. 2014;75:445-55.

74. Lindén C, Qvarlander S, Jóhannesson G, Johansson E, Östlund F, Malm J, et al. Normal-tension glaucoma has normal intracranial pressure. Ophthalmology. 2018;125:361-8. 
75. Pircher A, Remonda L, Weinreb RN, Killer HE. Translaminar pressure in Caucasian normal tension glaucoma patients. Acta Ophthalmol. 2017;95:e524-31.

76. Igarashi N, Honjo M, Asano S, Takagi K, Aihara M. Optic disc cupping characteristics of normal pressure hydrocephalus patients with normal-tension glaucoma. Sci Rep Nat Publ Group. 2019;9:3108.

77. Gallina P, Savastano A, Becattini E, Orlandini S, Scollato A, Rizzo S, et al. Glaucoma in patients with shunt-treated normal pressure hydrocephalus. J Neurosurg. 2018;129:1078-84.

78. Yablonski M, Ritch R, Pokorny K. Effect of decreased intracranial pressure on optic disc. Investig Ophthalmol Vis Sci. 1979;18:165.

79. Yang D, Fu J, Hou R, Liu K, Jonas JB, Wang H, et al. Optic neuropathy induced by experimentally reduced cerebrospinal fluid pressure in monkeys. Investig Opthalmology Vis Sci. 2014;55:3067.

80. Zhao D, He Z, Vingrys AJ, Bui BV, Nguyen CTO. The effect of intraocular and intracranial pressure on retinal structure and function in rats. Physiol Rep. 2015;3:e12507.

81. Bäuerle J, Schuchardt F, Schroeder L, Egger K, Weigel M, Harloff A. Reproducibility and accuracy of optic nerve sheath diameter assessment using ultrasound compared to magnetic resonance imaging. BMC Neurol. 2013;13:187.

82. Kavi T, Gupta A, Hunter K, Schreiber C, Shaikh H, Turtz AR. Optic nerve sheath diameter assessment in patients with intracranial pressure monitoring. Cureus. 2018;10:e3546.

83. Xu L, Wang $\mathrm{H}$, Wang $\mathrm{Y}$, Jonas JB. Intraocular pressure correlated with arterial blood pressure: the Beijing Eye Study. Am J Ophthalmol. 2007;144:461-2.

84. Mitchell P, Smith W, Attebo K, Healey PR. Prevalence of openangle glaucoma in Australia. The Blue Mountains Eye Study. Ophthalmology. 1996;103:1661-9.

85. Leske MC, Wu S-Y, Hennis A, Honkanen R, Nemesure B. Risk factors for incident open-angle glaucoma. Ophthalmology. 2008;115:85-93.

86. Topouzis F, Coleman AL, Harris A, Jonescu-Cuypers C, Yu F, Mavroudis L, et al. Association of blood pressure status with the optic disk structure in non-glaucoma subjects: the Thessaloniki Eye Study. Am J Ophthalmol. 2006;142:60-67.e1.

87. Hayreh SS. The role of age and cardiovascular disease in glaucomatous optic neuropathy. Surv Ophthalmol. 1999;43:S27-42.
88. Yilmaz KC, Sur Gungor S, Ciftci O, Akman A, Muderrisoglu H. Relationship between primary open angle glaucoma and blood pressure. Acta Cardiol. 2019;16:1-5.

89. Graham SL, Drance SM, Wijsman K, Douglas GR, Mikelberg FS. Ambulatory blood pressure monitoring in glaucoma. The nocturnal dip. Ophthalmol. 1995;102:61-9.

90. He Z, Nguyen CTO, Armitage JA, Vingrys AJ, Bui BV. Blood pressure modifies retinal susceptibility to intraocular pressure elevation. PLoS ONE Public Libr Sci. 2012;7:e31104.

91. Li M, Wang M, Guo W, Wang J, Sun X. The effect of caffeine on intraocular pressure: a systematic review and metaanalysis. Graefe's Arch Clin Exp Ophthalmol. 2011;249: 435-42.

92. Han M-E, Kim H-J, Lee Y-S, Kim D-H, Choi J-T, Pan C-S, et al. Regulation of cerebrospinal fluid production by caffeine consumption. BMC Neurosci BioMed Cent. 2009;10:110.

93. Basurto Ona X, Martínez García L, Solà I, Bonfill Cosp X. Drug therapy for treating post-dural puncture headache. Cochrane Database Syst Rev. 2011;10:CD007887.

94. Fraunfelder F, Fraunfelder FT, Corbett JJ. Isotretinoin-associated intracranial hypertension*1. Ophthalmology. 2004;111:1248-50.

95. de Botton S, Coiteux V, Chevret S, Rayon C, Vilmer E, Sanz M, et al. Outcome of childhood acute promyelocytic leukemia with all- trans-retinoic acid and chemotherapy. J Clin Oncol. 2004;22:1404-12.

96. Jacobson DM, Berg R, Wall M, Digre KB, Corbett JJ, Ellefson RD. Serum vitamin A concentration is elevated in idiopathic intracranial hypertension. Neurology. 1999;53:1114-8.

97. Tabassi A, Salmasi AH, Jalali M. Serum and CSF vitamin A concentrations in idiopathic intracranial hypertension. Neurology. 2005;64:1893-6.

98. Friedman DI, Gordon LK, Egan RA, Jacobson DM, Pomeranz $\mathrm{H}$, Harrison AR, et al. Doxycycline and intracranial hypertension. Neurology. 2004;62:2297-9.

99. Gardner K, Cox T, Digre KB. Idiopathic intracranial hypertension associated with tetracycline use in fraternal twins: case reports and review. Neurology. 1995;45:6-10.

100. Chiu AM, Chuenkongkaew WL, Cornblath WT, Trobe JD, Digre KB, Dotan SA, et al. Minocycline treatment and pseudotumor cerebri syndrome. Am J Ophthalmol. 1998;126: 116-21. 